\title{
Automation of the early stages of plating lines design
}

\author{
Vladimir Nemtinov ${ }^{1, *}$, Nikita Bolshakov ${ }^{1}$, and Yulia Nemtinova ${ }^{1}$ \\ ${ }^{1}$ Tambov State Technical University, 392000 Sovetskaya st. 106,Tambov, Russia
}

\begin{abstract}
In this paper we propose the procedure of automated selection of technological schemes for plating lines with specific operating conditions and criteria set by the customers using the theory of expert systems construction.
\end{abstract}

\section{Introduction}

Nowadays, many branches of national economy use plating to impart specific properties to components or final products. The main plating processes are protective and decorative coating. Companies working in the field of plating techniques are increasingly receiving orders for coating of small series or single details, but design of new plating lines requires substantial amount of time.

In order to significantly reduce the time for design of plating lines with customer-specified characteristics of end products, it is necessary to create an information system for automated solution of this task. Development of such systems allows: significant reduction in the use of supplies, replacing routine manual calculations with the software complex, visualization of all possible coating variants with final optimality ratings.

Analysis of literature sources in the field of plating lines design [1 - 11] has shown that no attention is paid to the automated selection of plating processes.

In this regard, the purpose of this work is to develop a procedure for automated synthesis of the structure of plating technological processes, which is implemented at the initial stage of plating lines design taking into account specific operating conditions of the final product and criteria set by the consumer.

In this case, the main input characteristics includes: type of detail, type of metal, purpose of coating, operating conditions.

The most advanced method for solving this problem is application of expert systems [1]. In order to choose an optimal variant of plating processes' structure, it is necessary to clearly define evaluation criteria, which are broken down into groups: costs, manufacturability, reliability and safety. In this case, it is recommended to use a comprehensive assessment, which is based on distribution of weights between these groups taking into account specific conditions.

\section{Problem statement for technological scheme selection}

In this paper, we propose the following statement of the problem for technological scheme selection for coating of metal products: it is required to find an optimal type of coating depending on consumer's requirements, which ensures the following equation:

$$
k_{\text {opt }}=\underset{k \in K}{\arg \min } Q_{1}(k)
$$

Since a multicriteria approach is used for selecting the optimal variant of technological scheme's structure, it is necessary to choose normalizing methods for the set of criteria and their ranking, as well as the method of multicriteria choice. In this paper, the optimality criterion $Q_{1}$ is the sum of weighted relative losses of the following criteria: criterion of discounted costs for plating stages implementation, criterion of reliability of system's functioning, criterion of manufacturability and criterion of safety [2].

The integral criterion $Q_{1}$ is equal to

$$
Q_{1}(k)=\sum_{i=1}^{4}\left(\rho_{i} \omega_{1 i}(k)\right) \text {. }
$$

Where $\rho_{1}, \rho_{2}, \rho_{3}, \rho_{4}$ - weight coefficients.

$$
\rho=\left\{\rho_{i}\right\}=\left\{\rho_{i}: \rho_{i}>0, i=1, \ldots, 4, \sum_{i=1}^{4} \rho_{i}=1\right\},
$$

where $\rho_{i} \omega_{1 i}(k)$ - weighted losses of the $i$-th criterion; $\omega_{1 i}(k)=\omega_{1 i}\left(F_{1 i}(k)\right), \quad(i=1, \ldots, 4, k \in K)-\quad$ monotonous functions that transform each objective function $F_{1 i}(k)$ to a dimensionless form; $F_{11}(k)$ - economic criterion, which includes agregate discounted costs on implementation of the system; $F_{12}(k)$ - criterion of reliability of system's functioning; $F_{13}(k), F_{14}(k)-$ criterion of manufacturability and criterion of safety, respectively. Notably, we should obtain minimum for the function $F_{11}(k)$ and maximum for the functions $F_{12}(k)$, $F_{13}(k), F_{14}(k)$.

Functions $\omega_{1 i}(k)(k \in K)$ are set as follows:

\footnotetext{
* Corresponding author: nemtinov@mail.gaps.tstu.ru
} 


$$
\begin{aligned}
& \omega_{11}(k)=\frac{F_{11}(k)-F_{11}^{0}}{F_{11}^{\max }-F_{11}^{0}}, \omega_{12}(k)=\frac{F_{12}^{0}-F_{12}(k)}{F_{12}^{0}-F_{12}^{\min }}, \\
& \omega_{13}(k)=\frac{F_{13}^{0}-F_{13}(k)}{F_{13}^{0}-F_{13}^{\min }}, \omega_{14}(k)=\frac{F_{14}^{0}-F_{14}(k)}{F_{14}^{0}-F_{14}^{\min }}
\end{aligned}
$$

Where $F_{11}^{\max }$ - maximal value of the minimizing function $F_{11}(k)(k \in K)$ on the set of acceptable values $K$; $F_{12}^{\min }, F_{13}^{\min }, F_{14}^{\min }$ - minimal values of the maximizing functions $F_{12}(k), F_{13}(k), F_{14}(k)(k \in K)$ on the set of acceptable values $K$; $F_{11}^{0}, F_{12}^{0}, F_{13}^{0}, F_{14}^{0}$ - optimal values of objective functions $F_{11}(k), F_{12}(k), F_{13}(k), F_{14}(k)$ $(k \in K)$ on the set of acceptable values $K$. The values $\omega_{1 i}(k)(i=1, \ldots, 4, k \in K)$ are within the limits from 0 to 1 .

Since in this paper the full enumeration method is used for searching of the optimal solution, it is not necessary to achieve the equality of weighted losses of $\rho_{i} \omega_{1 i}(k)$.

In order to choose a single solution to the problem, it is necessary to specify weight coefficients $\rho_{i}(i=\overline{1,4})$ that satisfy the equation (3) and reflect relative importance of the objective functions $F_{11}(k), F_{12}(k), F_{13}(k), F_{14}(k)$ $(k \in K)$. In this case the most effective methods are ranking and assigning of points [3].

When creating a database of plating methods, implementation of each stage is estimated (agregately) in terms of discounted costs. This economic criterion does not give the exact costs estimates, since at this stage there is only information about the stages of plating, on the basis of which it is possible estimate approximate costs of a particular techological scheme with the help of expert estimates [4]. The components of the criterion $F_{11}(k)$ are:

$$
F_{11}=\sum_{i=1}^{N_{k}} S_{i k}, k \in K
$$

Reliability is defined as the property of equipment to perform its specific functions, keeping in time the initial values of performance indicators within the specified limits, corresponding to the modes and operational conditions, maintenance and repair of the equipment:

$$
F_{12}=\max _{K} \prod_{i=1}^{N_{k}} P t_{i k}, k \in K
$$

Manufacturability of the process is its convenience and ease, the ability to perform the process (i.e. to obtain the required result) with the least labor expenditure ${ }^{\wedge}$

$$
F_{13}=\max _{K} \prod_{i=1}^{N_{k}} T e_{i k}, k \in K .
$$

Safety criterion is determined on the basis of indicators of the object's elements, which allow calculating the probability of fire and explosion hazards caused by the equipment:

$$
F_{14}=\max _{K} \prod_{i=1}^{N_{k}}\left(1-P b_{i k}\right), k \in K .
$$

Where $S_{i k}, P t_{i k}, T e_{i k}, P b_{i k}$ are the values of costs, manufacturability, reliability and safety for the $i$-th stage of the $k$-th variant of the technological scheme.

Criteria values are set by the experts for specific design conditions.

With the help of decision-making mechanism, it is possible to find a standard combination of technological stages that provide the required coating thickness at minimal cost.

\section{Information-logical model of decision- making support}

For a formalized descriptions of information arrays for solving of the problem (1) - (8), it is requred to create a structured database. Data structure for the studied subject area can be displayed by a set of information-logical models (ILM) and production models (PM) for decision-makig support. When constructing such models, data normalization requirements should be provided, and the models themselves should be presented in a canonical form.

In general, the ILM for decision-making support of plating stages selection with subsequent selection of appropriate hardware represents the union of data sets and relationships between them, written in the form of rules:

$$
\mathrm{M}=\langle D, P\rangle, D=\left(d_{1}, \ldots, d_{i}, \ldots, d_{N}\right), P=\left(p_{1}, \ldots, p_{j}, \ldots, p_{S}\right),
$$

where M - ILM operator, $d_{1}, \ldots, d_{N}$ - ILM data set, $p_{1}, \ldots, p_{S}$ - set of rules.

In turn, the rules for the model are constructed as follows: if ... (conditions are met), then ... (implementation of the result).

$$
\begin{gathered}
S_{\text {detail }}=\left\{S_{\text {detail }, 1}, \ldots, S_{\text {detail }, i}, \ldots, S_{\text {detail }, I}\right\} ; \\
P R_{\text {detail }}=\left\{p r_{\text {detail }, 1}, \ldots, p r_{\text {detail }, i}, \ldots, p r_{\text {detail }, I}\right\}, i=\overline{1, I} .
\end{gathered}
$$

In order to obtain the variants of plating, it is necessary to compile several databases of reference materials. A fragment of one of them is given in Table 1.

Further, queries to the database are formed as special conditional rules. Examples of the rules for selecting the type and thickness of coating for a deatil with a nonspecial form made of medium alloy carbon steel to be used under light operating conditions for corrosion protection will look as follows :

Rule 1: If for $s_{\text {detail, } 1}=$ "carbon steel" it is required to satisfy the properties $s_{\text {detail,6 }}=$ "protective coating" and $S_{\text {detail } 10}=$ "thickness of coating $0-0,5 \mu \mathrm{m}$ " and operating conditions $s_{\text {detail,18 }}=$ "to be used in normal conditions", than the plating method is $p r_{\text {detail }, 4}=$ "zinc coating".

Rule 2: If for $s_{\text {detail, } 1}=$ "carbon steel" it is required to satisfy the properties $s_{\text {detail,7 }}=$ "protective and decorative coating" and $s_{\text {detail, } 10}=$ "thickness of coating $0-0,5 \mu \mathrm{m}$ “ and operating conditions $s_{\text {detail,18 }}=$ "to be used in normal 
conditions", than the plating method is $p r_{\text {detail,4 }}=$ "cadmium coating".

Rule 3: If for $s_{\text {detal,2 }}=$ "corrosion-resisting steel" it is required to satisfy the properties $s_{\text {detail, } 6}=$ "protective coating" and $s_{\text {detail }, 10}=$ " thickness of coating $0-0,5 \mu \mathrm{m}$ " and operating conditions $s_{\text {detail,18 }}=$ "to be used in normal conditions", than plating method is $p r_{\text {detail }, 4}=$ "nickel coating".

Rule 35: If for $s_{\text {detail,1 }}=$ " medium alloy carbon steel"“ and $s_{\text {detail }, 5}=$ "protective coating" and $s_{\text {detail, } 11}=$ "to be used in light condtions", than the type and thickness of coating is $p r_{\text {detail }, 1}=$ "zinc coating of $6 \mu \mathrm{m}$ " and $p r_{\text {detail }, 2}=$ "nickel coating of $15 \mu \mathrm{m}$ ".

Table 1. Database fragment of coating types

\begin{tabular}{|c|c|c|c|c|c|}
\hline \multirow{2}{*}{\begin{tabular}{c}
\multirow{2}{*}{$\begin{array}{c}\text { Coating } \\
\text { metal }\end{array}$} \\
\multirow{2}{*}{ Type }
\end{tabular}} & \multicolumn{4}{|c|}{ Operating conditions } \\
\cline { 3 - 6 } & & light & mid & hard & extra \\
\hline $\mathrm{Zn}$ & $\begin{array}{c}\text { Corrosion } \\
\text { Protection }\end{array}$ & 6 & 15 & 15 & 15 \\
\hline $\mathrm{Nk}$ & $\begin{array}{c}\text { Corrosion } \\
\text { protection }\end{array}$ & 15 & 27 & - & - \\
\hline $\mathrm{Cu}+\mathrm{Sl}$ & $\begin{array}{c}\text { Reduce the } \\
\text { transient } \\
\text { resistance }\end{array}$ & $9 ; 3$ & $24 ; 9$ & $30 ; 9$ & - \\
\hline $\mathrm{Cr}$ & Friction & 18 & 36 & 48 & 60 \\
\hline $\mathrm{Nk}+\mathrm{Sn}$ & Soldering & $9 ; 3$ & $9 ; 18$ & - & - \\
\hline$\ldots$ & $\ldots$ & $\ldots$ & $\ldots$ & $\ldots$ & $\ldots$ \\
\hline
\end{tabular}

For each type of coating a separate database is created containing a set of standard technological operations of applying metal coating on details.

For example, for the input parameters specified above, the consumer will receive the types of metals that can cover a detail based on his requirements, their minimum thickness and the corresponding number of technological processes. For a specific example of input characteristics described above, the customer will see the chain of technological processes. A fragment of technological stages of zinc and nickel coating is given in the Table 2.

Each of the possible schemes is evaluated by an expert according to $\mathrm{F}_{11}-\mathrm{F}_{14}$ criteria. Thus, the consumer will receive visualized variants of processing a detail with calculated priority value for each of them. This will allow the user to select the best type of processing and to start designing technological processes with the exact constructive and regime parameters of the equipment shortly afterwards.

The fastest, most visualized and convenient way to create an information system is the PHP programming language with a DBMS in the Internet - MySQL. This method will not only provide a visual representation of information, but will also allow the users to work with the information system remotely and to integrate various modules into it.

The procedure of automated synthesis of technological schemes of plating stages with the use of expert systems theory suggested in this paper allows users to choose the most suitable technological schemes of plating lines for specific operating conditions and consumer's criteria in the cases of high dimensionality of possible variants. Such a procedure can be used for the subsequent design of technological processes of plating of metal details with determination of precise regime and design parameters of the equipment.

Table 2. Database fragment of coating stages

\begin{tabular}{|c|c|}
\hline Zinc coating & Nickel coating \\
\hline $\begin{array}{l}\text { 1. Chemical } \\
\text { degreasing }\end{array}$ & $\begin{array}{l}\text { 1. Chemical } \\
\text { degreasing }\end{array}$ \\
\hline $\begin{array}{l}\text { 2. Electrochemical } \\
\text { degreasing: cathode } \\
\text { and anode }\end{array}$ & $\begin{array}{l}\text { 2. Electrochemical } \\
\text { degreasing: } \\
\text { cathode and anode }\end{array}$ \\
\hline $\begin{array}{l}\text { 3. Rinsing with warm } \\
\text { flowing water. }\end{array}$ & $\begin{array}{l}\text { 3. Rinsing with } \\
\text { warm flowing } \\
\text { water. }\end{array}$ \\
\hline $\begin{array}{l}\text { 4. Rinsing with cold } \\
\text { flowing water. }\end{array}$ & $\begin{array}{l}\text { 4. Rinsing with } \\
\text { cold flowing water. }\end{array}$ \\
\hline 5. Etching. & 5. Etching. \\
\hline 6. Activation. & 6. Activation. \\
\hline $\begin{array}{l}\text { 7. Rinsing with cold } \\
\text { flowing water. }\end{array}$ & $\begin{array}{l}\text { 7. Rinsing with } \\
\text { cold flowing water. }\end{array}$ \\
\hline 8. Zinc coating. & 8. Nickel coating. \\
\hline $\begin{array}{l}\text { 9. Rinsing with warm } \\
\text { flowing water. }\end{array}$ & $\begin{array}{l}\text { 9. Rinsing with } \\
\text { warm flowing } \\
\text { water. }\end{array}$ \\
\hline $\begin{array}{l}\text { 10. Two-stage rinsing } \\
\text { with cold flowing } \\
\text { water. }\end{array}$ & $\begin{array}{l}\text { 10. Two-stage } \\
\text { rinsing with cold } \\
\text { flowing water }\end{array}$ \\
\hline 11. Clearing. & 11. Drying. \\
\hline $\begin{array}{l}\text { 12. Etching in } \\
\text { chrome pickle. }\end{array}$ & \\
\hline $\begin{array}{l}\text { 13. Rinsing with cold } \\
\text { non-flowing water. } \\
\text { (trapping). }\end{array}$ & \\
\hline $\begin{array}{l}\text { 14. Rinsing with cold } \\
\text { flowing water. }\end{array}$ & \\
\hline 15. Drying. & \\
\hline
\end{tabular}

Approbation of the proposed approach to selection of the technological scheme's structure for plating lines was carried out on the example of details with the following characteristics: material - carbon steel; purpose of details - to be used in industry, in contact with air, one-time contact with water (moisture, rain); purpose of coating - to implement protective properties 
against corrosion; required coating thickness is $10 \mu \mathrm{m}$; operating conditions of the coated part - normal climatic conditions. As a result of solving the problem of technological scheme selection zinc coating scheme was chosen (see Table 2).

\section{Results and discussion}

The procedure of automated synthesis of technological schemes for plating stages with the use of expert systems theory suggested in this paper allows users to choose the most suitable scheme for specific operating conditions and consumer's criteria.

\section{References}

1. T. Tanaka, J. Ohwi, L.V. Litvintseva, S.V. Ulyanov, Soft computing. L(2), 88-95 (1997).

2. E.N. Malygin, V.A. Nemtinov, Yu.V. Nemtinova, Theor. Found. Chem. Eng. 2003. 37(№ 6), 613-618 (2003).

3. Seong-Joo Kim, Woo -Kyoung Choi, and Hong-Tae M.Gh. Negoita et al., (Eds.): KES 2004, LNAI 3215, P. 589 (2004)

4. V.G. Mokrozub, V.A. Nemtinov, Chemical and petroleum engineering 51(7-8), 31-35 (2015).

5. W.M. Cheung, P.G. Maropoulos, International Journal of Computer Applications in Technology, V. 37(3-4), 182-193 (2010).

6. J.M. Wang, L. Zhang, Y.B. Liu, X.N. Mo, G.Q. Ren, Computer Integrated Manufacturing Systems, CIMS. 16(10), 2017-2023 (2010).

7. V.G. Mokrozub, K.D. Manuilov, V.V. Gorshkov, T.S. Gorshkova, Chemical and Petroleum Engineering 51(9-10), 613- 617 (2016).

8. V.A. Nemtinov, Yu.V. Nemtinova, Journal of Computer and Systems Sciences International 44(3), 389- 397 (2005).

9. Yu.V. Litovka, D.S. Solovjev, Transactions of the Tambov State Technical University 18(1), 128-135 (2015) (In Russ., abstract in Eng.)

10. Yu.V. Litovka, V.Z. Cao, Transactions of the Tambov State Technical University 22(1), 68-74 (2016) (In Russ., abstract in Eng.)

11. V.V. Konkina, D.S. Solovev, Yu.V. Litovka, Transactions of the Tambov State Technical University, 21(2), 248-256 (2015) (In Russ., abstract in Eng.) 